\title{
Chitosan/Graphene Oxide Composite Films and Their Biomedical and Drug Delivery Applications: A Review
}

\author{
Sara Moradi ${ }^{1}$, Hamid Hamedi ${ }^{2}$, Alan E. Tonelli ${ }^{2, *}$ and Martin W. King ${ }^{2,3, *}$ \\ 1 Department of Chemical Engineering, Faculty of Engineering, Arak University, Arak 39455, Iran; \\ smoradi.phd@gmail.com \\ 2 Textile Engineering Chemistry and Science, Wilson College of Textiles, North Carolina State University, \\ Raleigh, NC 27606, USA; hhamedi@ncsu.edu \\ 3 College of Textiles, Donghua University, Songiiang District, Shanghai 201600, China \\ * Correspondence: atonelli@ncsu.edu (A.E.T.); mwking2@ncsu.edu (M.W.K.)
}

Citation: Moradi, S.; Hamedi, H.;

Tonelli, A.E.; King, M.W.

Chitosan/Graphene Oxide

Composite Films and Their Biomedical and Drug Delivery Applications: A Review. Appl. Sci. 2021, 11, 7776. https://doi.org/ 10.3390/app11177776

Academic Editor: David G. Calatayud

Received: 10 June 2021

Accepted: 19 August 2021

Published: 24 August 2021

Publisher's Note: MDPI stays neutral with regard to jurisdictional claims in published maps and institutional affiliations.

Copyright: (C) 2021 by the authors. Licensee MDPI, Basel, Switzerland. This article is an open access article distributed under the terms and conditions of the Creative Commons Attribution (CC BY) license (https:// creativecommons.org/licenses/by/ $4.0 /)$.

\begin{abstract}
The healing of wounds is still a challenging clinical problem for which an efficient and fast treatment is needed. Therefore, recent studies have created a new generation of wound dressings that can accelerate the wound healing process with minimal side effects. Chitosan, a natural biopolymer, is an attractive candidate for preparing biocompatible dressings. The biodegradability, non-toxicity, and antibacterial activities of chitosan have made it a promising biopolymer for treating wounds. Graphene oxide has also been considered by researchers as a non-toxic, inexpensive, and biocompatible material for wound healing applications. This review paper discusses the potential use of chitosan/graphene oxide composite films and their application in wound dressing and drug delivery systems.
\end{abstract}

Keywords: chitosan; graphene oxide; wound dressings; drug delivery

\section{Introduction}

The creation of smart wound dressings that work proactively with the human body to speed up the wound healing process and prevent infection has received more attention recently, particularly for individuals with chronic wounds. Due to the need for a new generations of smart wound dressings with the ability to accelerate the wound healing process and prevent infections, various kinds of dressings with novel materials and structures have been prepared and studied. In particular, biopolymers have attracted more interest due to their biocompatibility and low or non-toxicity.

Chitosan is one of the most attractive biopolymers for wound dressing applications. It is a linear polysaccharide derived from chitin, which is the second most abundant biopolymer after cellulose. It has antimicrobial, anticoagulant, antibacterial, antifungal, anti-tumor, and hemostatic properties [1]. Due to these excellent characteristics, chitosan has long been a potential biomaterial for biomedical applications such as wound dressings [2], drug delivery systems, and tissue-engineering scaffolds [3]. Graphene oxide (GO) is one of the most important derivatives of graphene. In recent years, it has been considered as a suitable material for biomedical applications. Owing to its large surface area and functional groups, such as carboxyl and hydroxyl, GO is hydrophilic in nature, so it can be dispersed in aqueous solutions via electrostatic repulsion [4]. GO can be applied to reinforce natural polymers such as chitosan, and some reports have indicated that chitosan/GO composites can capitalize on the advantages of both chitosan and GO materials [5]. Therefore, there are several studies regarding the preparation and characterization of chitosan/GO composite films and their application in different biomedical fields, such as wound dressing and drug delivery systems. This review highlights the applications of chitosan/GO composites as wound dressings and drug delivery systems. First, the individual properties of chitosan 
and graphene oxide are described. Then, different hybrid chitosan/GO structures such as hydrogels and electrospun nanofibers are discussed.

\section{Chitosan}

The general term chitosan describes a range of poly-(beta-1-4) N-acetyl-D-glucosamine materials (Figure 1) whose properties are highly dependent on the degree of deacetylation, average molecular weight, polydispersity, morphology, and chemical structure. Chitosan is one of the most widely used materials for biomedical end-uses, including wound dressing applications [6-9]. It has excellent biocompatibility and low toxicity, and can stimulate a positive immune response, as described in our previous review paper about applications for chitosan hydrogels as wound dressing materials [1].

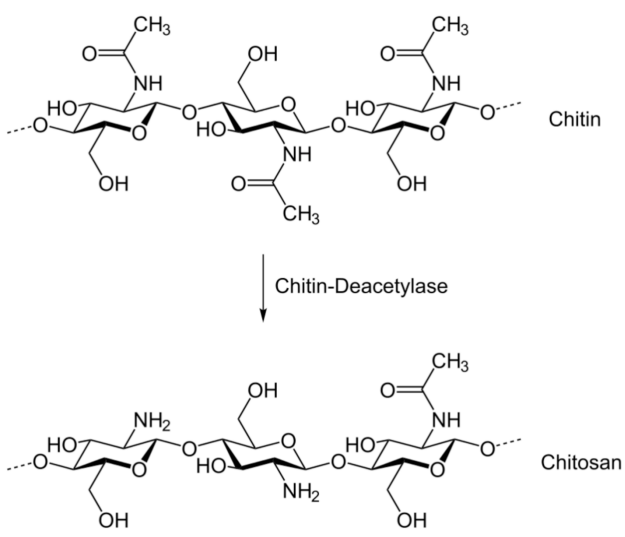

Figure 1. Chitosan structure [1].

\section{Graphene Oxide}

Graphene, also known as graphite, consists of a single layer of carbon atoms arranged in a two-dimensional honeycomb lattice. Graphene oxide is composed of carbon, oxygen, and hydrogen in variable ratios, obtained by treating graphene with strong oxidizing agents (Figure 2). The structure and properties of graphene oxide depend on the method of synthesis and the degree of oxidation. It usually maintains the single layer structure of graphene, but the layers are buckled and the space between the layers is about two times larger $(\sim 0.7 \mathrm{~nm})$ than that of graphene. Graphene oxide can be considered a promising candidate for biological and biomedical applications because of its amphiphilicity, aqueous processability, ease of surface functionalization, and its capacity for fluorescence quenching [10].

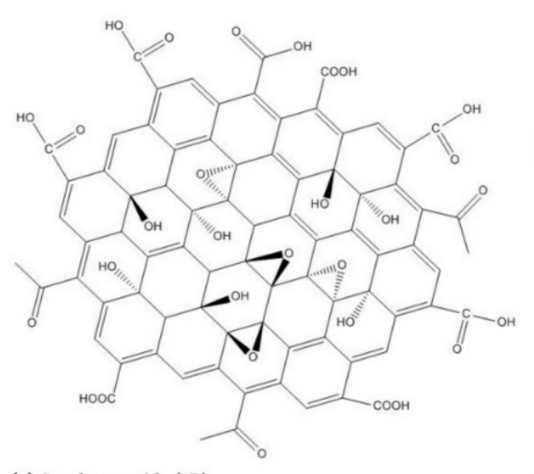

(a) Graphene oxide (2D)

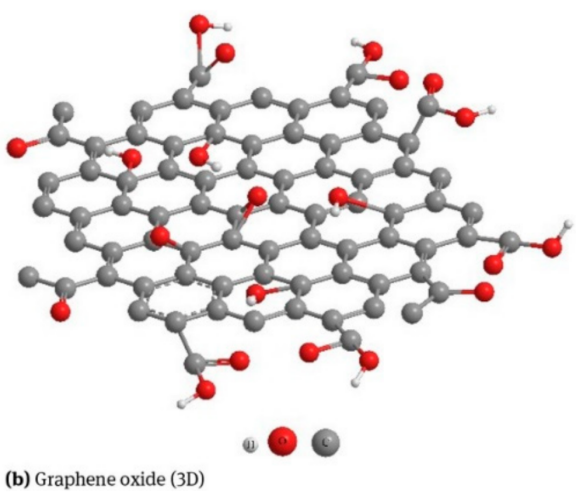

(b) Graphene oxide (3D)

Figure 2. Graphene oxide [11]. 


\subsection{Toxicity and Biocompatibility}

The toxicity of graphene oxide (GO) has been studied by several researchers. In a study undertaken by Chang et al. [12] evaluating the toxicity of GO on A549 human lung cells, it was shown that GO does not enter the A549 cell and causes no evident cytotoxicity. However, based on the applied dose, it can lead to oxidative stress in cells and some loss of cell viability at high concentrations. LiQiang et al. [13] showed that GO has a moderate level of toxicity to human bone marrow neuroblastoma cells and human epithelial carcinoma cells. When studied with zebrafish (Danio rerio) embryos, a $20 \%$ inhibition in cell growth was observed. Additionally, when a high dosage of $50 \mathrm{mg} / \mathrm{L}$ was used, this caused a delay in the hatching of the zebrafish embryos, but it did not increase apoptosis significantly. Majidi et al. [14] synthesized GO-chitosan nanohybrid films for wider biomedical applications and characterized the film's structure, antibacterial activity, and cytotoxicity. The results of the antibacterial tests showed that GO-chitosan hybrids had greater antibacterial activity compared to that of pure GO. Additionally, the attachment of graphene sheets to GO decreased the level of cytotoxicity and, in some cases, led to increased cell proliferation. In another study, Liao et al. [15] evaluated the cytotoxicity of GO and graphene sheets with different sizes and oxygen levels on human red blood cells and adherent skin fibroblasts using WST-8 viability and hemolysis assays. The results of the WST- 8 assay and hemolysis data proved that compact graphene sheets were more toxic to mammalian fibroblasts than the less dense graphene oxide. Additionally, the graphene sheets produced more reactive oxygen species on the surface of the dermal fibroblasts. They concluded that the toxicity of graphene and graphene oxide depended on the exposure environment, such as the level of aggregation and the type of cell interaction (i.e., cell suspension versus adherent cells). Exposure of reduced graphene oxide (rGO) particles with a diameter between 100 and $110 \mathrm{~nm}$ and a thickness between 3 and $5 \mathrm{~nm}$ to human PC12 neuronal cells increased the activation of caspase- 3 , the release of lactate dehydrogenase, and the generation of reactive oxygen species. However, rGO had a moderate effect on protein levels during contact with human HepG2 hepatoma cells [16]. According to the literature, the toxicity of GO and rGO is strongly dependent on their concentration, and increases with the amount of GO or rGO. For instance, a GO concentration greater than $50 \mu \mathrm{g} / \mathrm{mL}$ showed toxicity to human fibroblasts, decreased the amount of cell adhesion, and promoted cell apoptosis [17].

Liao et al. [15] also investigated the blood compatibility of GO and graphene sheets on human red blood cells and adherent skin fibroblasts. The observed level of hemolysis for the GO samples was strongly dependent on the extent of exfoliation of the injured dermal tissue and particle size. Smaller-sized GO particles had a higher hemolytic activity compared to larger sized GO particles. Their results demonstrated that the size, shape, and density of the graphene particles, oxygen content, and electrostatic charge on the surface of the particles strongly affected the toxicological and biological responses by red blood cells. They also found that covering GO with chitosan removed any hemolytic activity. Zhang et al. [18] investigated the biocompatibility and distribution of GO in mice. The results showed that GO did accumulate in the lungs over an extended period of time. GO also contributed to a slower blood circulation time, with $5.3+1.2 \mathrm{~h}$ half-life compared to other carbon nanomaterials. When the mice were exposed to $1 \mathrm{mg} \mathrm{kg}^{-1}$ body weight of GO for 14 days, no pathological changes were observed in the examined organs. GO exhibited good biocompatibility with red blood cells. The conclusions recommended that GO in low doses is an acceptable candidate for biomedical applications, but when the dosage exceeds $10 \mathrm{mg} \mathrm{kg}^{-1}$ body weight, some pathological changes, such as pulmonary edema, chronic inflammation, and granuloma formation, are likely to occur. Based on a review report by Kiew et al. [19], after incubation for $3 \mathrm{~h}$, the micro-sized $(3 \mu \mathrm{m})$ graphene sheets $(10 \%$ hemolysis at $100 \mu \mathrm{g} / \mathrm{mL})$ caused less hemolysis than nano-sized GO $(350 \mathrm{~nm})$ particles $(70 \%$ at $25 \mu \mathrm{g} / \mathrm{mL})$. The superior hemocompatibility of the smaller-sized graphene oxide sheets was no doubt due to the limited overall surface area available for interaction with red blood cells. 
Chen et al. [3] also investigated the biocompatibility of the PVA/CS/modified GO (mGO) films by measuring viability of $\mathrm{HaCaT}$ cells after seeding on the surfaces of different concentrations of composite films (Figure 3). The PVA/CS/1.0 wt $\% \mathrm{mGO}$ film could lead to some detrimental effects on $\mathrm{HaCaT}$ cell viability after 5 days, and no remarkable differences in cell viability of other films were observed, indicating that films with concentrations below $0.5 \mathrm{wt} \% \mathrm{mGO}$ had no obvious in vitro cytotoxicity.

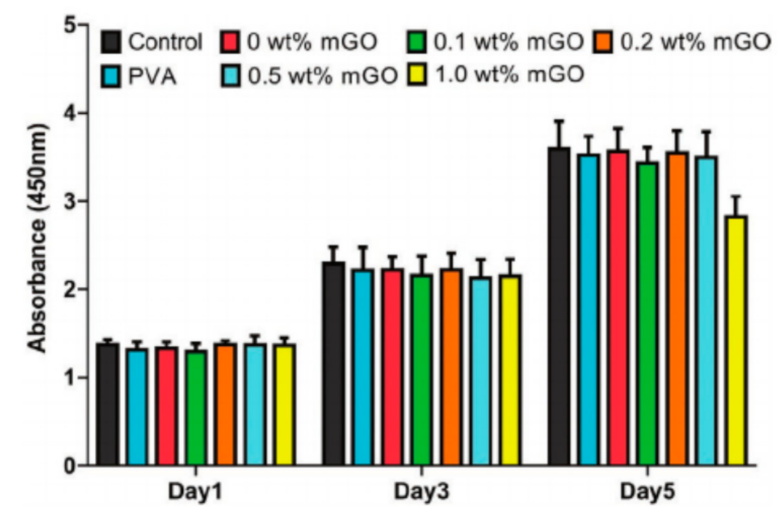

Figure 3. Cell viability of modified GO-loaded films with different concentrations [3].

Mouse preosteoblast cells seeded in contact with chitosan/GO 0.5 and $3 \mathrm{wt} \%$ had a significantly $(p<0.001)$ higher rate of viability and proliferation than the ones in contact with chitosan control after 2 days of culture (Figure 4). This can be related to the presence of GO, which could have a role in increasing cells' metabolic activity and proliferation [20].

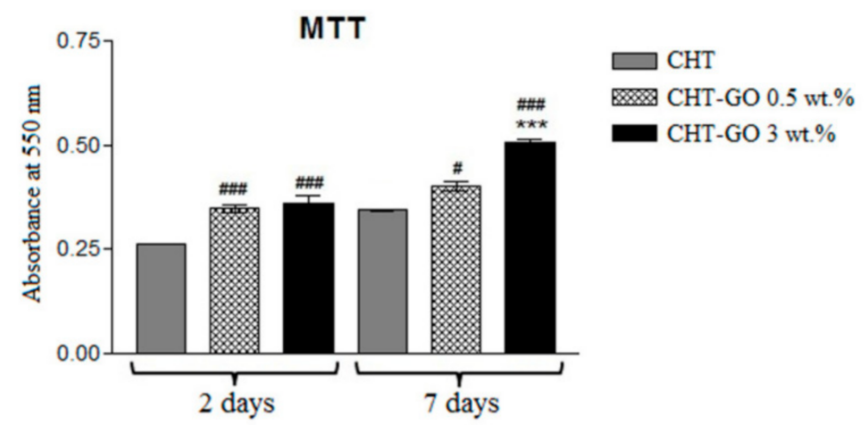

Figure 4. Quantification of MC3T3-E1 preosteoblast metabolic activity in contact with chitosan and chitosan/GO films. Statistical significance: \# $p<0.05$ (CHT/GO $0.5 \mathrm{wt} \% 7$ days vs. CHT 7 days); \#\#\# $p<0.001$ [(CHT/GO $0.5 \mathrm{wt} \% 2$ days vs. CHT 2 days); (CHT/GO $3 \mathrm{wt} \% 2$ days vs. CHT 2 days); (CHT/GO $3 \mathrm{wt} \% 7$ days vs. CHT 7 days)]; ${ }^{* * *} p<0.001$ (CHT/GO $3 \mathrm{wt} \% 7$ days vs. CHT/GO $0.5 \mathrm{wt} \%$ 7 days) [20].

\subsection{Biomedical Properties}

A study by Mukherjee et al. [21] showed that the activation of inflammasomes does not depend on the lateral dimensions of GO sheets. Inflammasomes, are receptors/sensors of the innate immune system that regulate the activation of caspase- 1 and are responsible for the activation of inflammatory responses, such as IL-1 $\beta$ [1]. Mukherjee et al. [21] also show that when GO sheets (small and large) are exposed to primary human macrophages, they are not cytotoxic for primary human macrophages and do not trigger a typical Th1 cytokine (i.e., TNF- $\alpha$, IL-6, or IL-1 $\beta$ ) or Th2 cytokine (i.e., IL-4, IL-5, and IL-13) response in macrophages. From these observations, it was concluded that endotoxin-free GO is biocompatible and proinflammatory.

GO can be gradually degraded through enzyme-induced oxidization by, for example, horseradish peroxidase (HRP). Due to the remote possibility of toxicity to macrophages, 
coating GO with biocompatible macromolecules can be a method to reduce its level of cytotoxicity. However, at the same time, coating can limit the degradability of GO due to steric hindrance. Therefore, more recent studies have attempted to design a surface-modified GO carrier that will degrade and provide drug delivery functionality while maintaining an acceptable level of toxicity [22,23]. In one study conducted by Tavakoli et al. [24], chitosan film completely degraded in 3 days, while chitosan/GO films degraded after 28 days. By adding a small amount of $\mathrm{GO}$, and through an interaction of the $\mathrm{COOH}$ functional groups of GO with chitosan, crystallinity of the composite film increases, leading to reduction in the degradation rate, which make it a good candidate for bone replacement in orthopedic applications. In another study, enzymatic hydrolysis in the presence of lysozyme was performed for evaluation of biodegradability of chitosan/GO films. It was observed that the degradability of the chitosan decreased by increasing the amount of GO, which is probably because GO sheets postpone the penetration of the enzyme inside a polymer matrix [25].

Gurunathan et al. [26] investigated the antibacterial activity of GO and reduced graphene oxide (rGO) against $P$. aeruginosa. rGO sample was synthesized from GO using betamercapto-ethanol (BME) as a novel reducing agent, which is known to be less cytotoxic than hydrazine. The results showed that both GO and rGO had significant antibacterial activity in a concentration- and time-dependent manner. They also realized that oxidative stress is a key mechanism for antibacterial activity of GO and rGO. In another study by Liu et al. [27], the antibacterial activity of GO sheets with different sizes and shapes was evaluated against Escherichia coli. The results indicated that the antibacterial activity of GO depended on the specimen's lateral size. Larger-sized GO sheets had more antibacterial activity compared to smaller-sized ones. They also had different time- and concentrationdependent antibacterial activities. The antibacterial activity of different graphene-based materials, including graphite $(\mathrm{Gt})$, graphite oxide $(\mathrm{GtO})$, graphene oxide $(\mathrm{GO})$, and reduced graphene oxide (rGO), were investigated against Escherichia coli, and the results showed that GO had the highest antibacterial activity, followed by rGO, Gt, and GtO [28].

Angiogenesis is another key property to accelerate the wound healing process. Ozkan et al. demonstrated that GO and rGO have promising angiogenesis properties [29]. A combination of GO and other polymers, such as GelMA [30] and chitosan [31], provides an attractive method to accelerate the wound healing process by promoting angiogenesis. Reactive oxygen species (ROS) in biological systems play an important role in angiogenesis. Both GO and rGO can increase the concentration of ROS, and ROS can also act as signaling molecules as part of the growth factor-mediated physiological response to cell proliferation and wound healing [30].

\subsection{Electrical Conductivity}

Graphene also has unique optical, electrical, and thermal characteristics that make it suitable for a range of different applications, such as biosensors, transparent conductors, and drug diagnostics. Both $\mathrm{GO}$ and rGO have residual functional groups, leading to faster heterogeneous electron transfer on the surface and better biocompatibility, dispersibility and charge transfer than is possible with pure graphene [32]. Several studies have demonstrated the effect of electrical conductivity of GO in combination with other polymers and its applications. Ozkan et al. prepared chitosan/rGO nanocomposites with appropriate levels of conductivity, stability, charge density, and electrochemical properties for designing molecular detection systems [32]. In another study, chitosan and reduced graphene oxide sheets with a high conductivity of $1.28 \mathrm{~S} \mathrm{~m}^{-1}$ were fabricated for various biological applications, such as biosensors and tissue-engineering scaffolds [33]. Highly reduced few-layer graphene oxide films with conductivities of up to $500 \mathrm{~S} \mathrm{~cm}^{-1}$ were obtained by Betriu et.al [34]. Conductivity is strongly dependent on the properties of GOs (as these determine the effectiveness of the chemical reduction), structural and morphological defects of the flakes, and connectivity. Electrically conductive chitosan/GO based scaffolds have been prepared for cardiac tissue-engineering end-uses [35,36]. Additionally, the electrical 
conductivity of GO has been found to be highly desirable for use as biosensors [37,38], supercapacitors [39,40], and cardiovascular tissue-engineering scaffolds [41,42].

\section{Chitosan/Graphene Oxide Films for Biomedical Applications}

Due to their electronegativity, graphene oxide can easily interact with cationic polymers, such as chitosan, which may lead to a reduction in toxicity and enhanced mechanical properties of the composite structure. For example, loading $1 \mathrm{wt} \%$ of GO can improve tensile strength from 43.2 MPa (pure chitosan) to 104.2 MPa (Chitosan/GO). This should be attributed to the effective load transfer between GO and chitosan coming from good interfacial properties after cross-linking. [43]. With respect to the specific properties of chitosan/graphene oxide blends, there are a series of different wound dressing studies with alternative techniques for the preparation of the chitosan/GO composites, which are classified and discussed in the following sections.

\subsection{Chitosan/Graphene Oxide Hydrogels}

Hydrogels are cross-linked and three-dimensional structures that can absorb water and biological liquids without dissolving or losing their 3D network. They are able to absorb and hold high levels of exudate and can be separated from a wound's surface with minimal pain. Fan et al. [44] prepared composite hydrogels from oxidized konjac glucomannan (OKGM) and carboxymethyl chitosan (CMCS) with different concentrations of graphene oxide $(\mathrm{GO})$ as a nano-additive. Hydrogels have a 3D structure with a fast gelation time, good water retention capacity, and a high swelling ratio. The compressive modulus and strength were significantly enhanced by adding GO, which was due to the increased hydrogen bonding between the polymer chains and the GO. An in vitro cytotoxicity assay showed that the samples loaded with $\mathrm{GO}$ had better biocompatibility compared to those without GO, from which it was concluded that the prepared hydrogels could be considered as potential wound dressings.

Another type of wound dressing was developed by loading polyhexamethylene guanidine (PHMG)-modified graphene oxide (mGO) into a polyvinyl alcohol/chitosan (PVA/CS) matrix [3]. The dressings had good mechanical properties, shorter swelling time, higher water vapor transmission rate (WVTR), faster cell proliferation, and greater antibacterial activity compared to those without $\mathrm{mGO}$. The average wound closure time for the films loaded with mGO was $8.2 \pm 0.4$ days, which was significantly shorter than the Vaseline gauze control and the hydrogels without $\mathrm{mGO}$ (about 14 days). An in vivo trial confirmed that this novel composite PVA/CS/mGO film had the ability to accelerate wound healing, and therefore showed promise in wound dressing applications.

Layered nanocomposite hydrogel films containing chitosan and GO were prepared for use in biomedical applications by Zhang et al. [45]. The resultant hydrogels had superior mechanical properties and a $\mathrm{pH}$-driven shape memory effect. Shape memory polymers are stimuli-responsive materials that can maintain a temporary deformed shape, but then return to their original permanent shape when exposed to external stimuli. In this study, the initial shapes of the CS and CS/GO hydrogels were straight strips. After 5 min of immersion in $\mathrm{pH} 3$ solution, the films could be easily deformed and bent into a " $\mathrm{U}$ " shape by an external applied stress, and kept in that shape at $\mathrm{pH} 12$ aqueous solution for $10 \mathrm{~min}$. The deformed and bent films were then transferred back to $\mathrm{pH} 3$ solution and, as can be seen from Figure 5, the CS/GO hydrogel reverted to its original shape in $9 \mathrm{~min}$, whereas the CS hydrogel strip did not return to its original straight shape in more than $15 \mathrm{~min}$. The shape fixity ratio of the hydrogels with $5 \mathrm{wt} \%$ GO was about $99 \%$ compared to $86 \%$ for the pure CS film. These results demonstrated that the prepared films could be combined with hydrogels for biomedical applications such as wound dressings. 
(a)

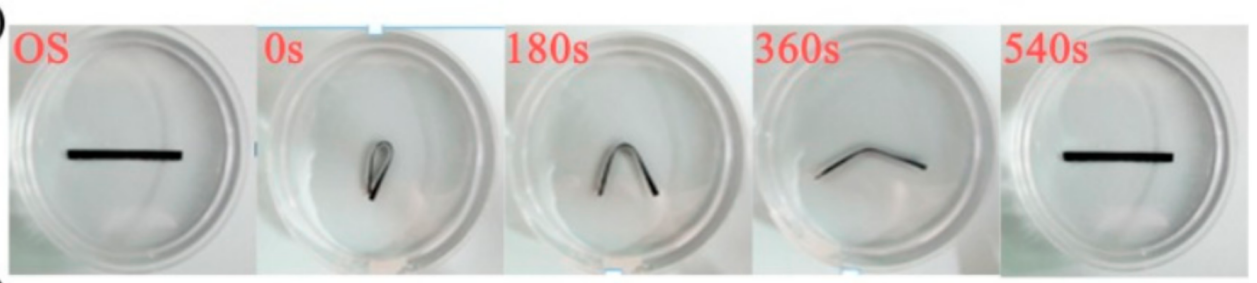

(b)

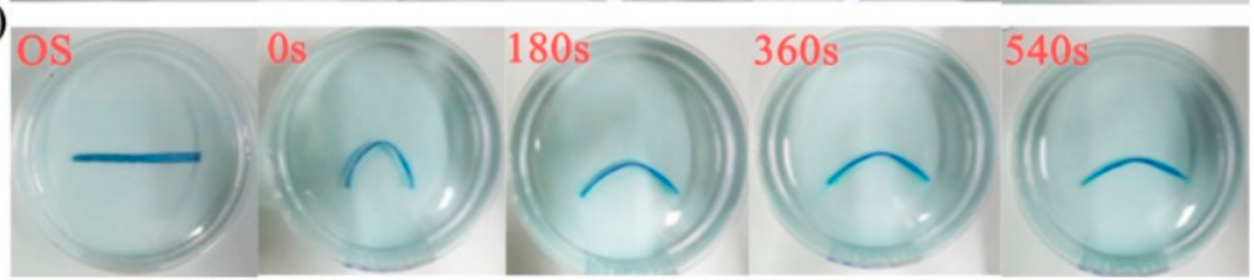

Figure 5. Photographs of $\mathrm{pH}$-driven shape memory polymer samples (a) CS/5 wt \% GO and (b) pure CS. The CS strip was coated with methylene blue for better visibility. OS: original sample [45].

Several other studies involving the preparation of chitosan/GO hydrogels are listed in Table 1.

Table 1. Chitosan/GO hydrogels and their biomedical applications.

\begin{tabular}{|c|c|c|c|}
\hline Ingredients & $\begin{array}{c}\text { Potential } \\
\text { Applications }\end{array}$ & Characterization & Reference \\
\hline $\begin{array}{l}\text { Chitosan/GO/ } \\
\text { curcumin }\end{array}$ & Wound dressings & $\begin{array}{c}\text { Improved Young's modulus } \\
\text { Improved antibacterial activity and } \\
\text { in vitro release after addition of } \\
\text { curcumin } \\
\text { Greater proliferation of NIH/3T3 } \\
\text { fibroblast cells } \\
\text { GO/curcumin increased hydrophilic } \\
\text { properties }\end{array}$ & [46] \\
\hline $\begin{array}{c}\text { Chitosan/iron } \\
\text { oxide/GO }\end{array}$ & $\begin{array}{c}\text { Biomedical } \\
\text { Applications }\end{array}$ & $\begin{array}{l}\text { Improved thermal and mechanical } \\
\text { properties } \\
\text { Significant antimicrobial activities } \\
\text { Non-cytotoxic }\end{array}$ & [47] \\
\hline $\begin{array}{l}\text { Carboxymethyl } \\
\text { chitosan/GO/ } \\
\text { polyacrylamide }\end{array}$ & $\begin{array}{l}\text { Bioengineering and } \\
\text { drug delivery } \\
\text { systems }\end{array}$ & $\begin{array}{c}\text { Excellent mechanical performance } \\
\text { Biocompatible } \\
\text { Fast recovery }\end{array}$ & [48] \\
\hline $\begin{array}{c}\text { Quaternary } \\
\text { chitosan/ } \\
\text { cyclodextrin/GO }\end{array}$ & Wound dressings & $\begin{array}{l}\text { Similar conductivity with that of skin } \\
\text { and rapid self-healing behavior } \\
\text { Superior antibacterial property } \\
\text { Accelerated in vivo wound healing } \\
\text { Good biocompatibility }\end{array}$ & [49] \\
\hline $\begin{array}{l}\text { Carboxymethyl- } \\
\text { hexanoyl } \\
\text { chitosan/GO/ } \\
\text { cellulose } \\
\text { nanocrystals }\end{array}$ & Wound dressings & $\begin{array}{c}\text { Excellent biocompatibility } \\
\text { Superior antibacterial properties } \\
\text { High water absorption capacity and } \\
\text { water retention capability } \\
\text { GO/cellulose increased hydrophilic } \\
\text { properties }\end{array}$ & [50] \\
\hline $\begin{array}{l}\text { Poly } \\
\text { (p-phenylene } \\
\text { sulfide)/ } \\
\text { chitosan/rGO }\end{array}$ & $\begin{array}{l}\text { Wound Tissue } \\
\text { Engineering }\end{array}$ & $\begin{array}{l}\text { Acceptable biocompatibility and cell } \\
\text { attachment } \\
\text { Swelling ratio and WVTR * decreased } \\
\text { by adding PPS **/rGO } \\
\text { Improved mechanical properties }\end{array}$ & [51] \\
\hline
\end{tabular}




\subsection{Chitosan/Graphene Oxide Nanofibers}

Due to the similarity of their structure to the extracellular matrix, electrospun chitosan/graphene oxide nanofiber webs can promote cell adhesion, proliferation, and migration and, as a result, they can be considered as an attractive candidate for wound dressing applications. They can act as a barrier to the contamination of open wounds from exogenous microorganisms, and they can maintain the moisture of a wound's surface to promote the wound healing process. Electrospun nanofibers have a high surface area, which makes them ideal for use in drug delivery systems [52].

Yang et al. [52] prepared chitosan/polyvinyl alcohol/graphene oxide (CS/PVA/GO) nanofibers loaded with antibiotic drugs, such as ciprofloxacin and ciprofloxacin hydrochloride, by using an electrospinning technique. The drug release results showed a controlled release without an initial burst. Adding GO moderately improved the drug release ratio. The drug-loaded nanofibers had significant antibacterial activity against both Gramnegative and Gram-positive bacteria, as well as cytocompatibility with melanoma cells. In another study, by increasing the GO content in the electrospun antibacterial CS/PVA/GO, nanofibers were found to decrease the thermal stability of hybrid composite nanofibers [53]. The nanofiber web had effective antibacterial activity against both Gram-negative and Gram-positive bacteria, suggesting that the electrospun nanofiber web could be used as a wound dressing. The natural garlic extract, allicin, with its strong antibacterial activity, was loaded into the electrospun chitosan/polyvinyl alcohol/GO nanofibers, and the release study showed that the amount of allicin released could be controlled by GO content. The drug-loaded nanofibers had effective antibacterial activity against Staphylococcus aureus, and the nanofibers containing GO had superior antibacterial activity compared to those without GO. The drug-loaded nanofibers also had a significant moisture-retention capacity and hygroscopicity and, as a result, these nanofibers were considered to be potential candidates for wound dressing and tissue-engineering applications.

In another study, multi-component nanofiber webs loaded with various antibacterial agents, such as silver nanoparticles (Ag), graphene oxide (GO), curcumin (CUR), and chitosan (CS), were prepared [2]. First, PEGylated GO was used as the template to synthesize a series of PEGylated GO/Ag/CUR nanocomposites by incorporating them into CS/polyvinyl alcohol nanofibers (Figure 6). The results from an antibacterial test indicated improved effectiveness compared to other formulations. The GO increased the mechanical properties of the nanofibers, with a tensile strength of $25 \mathrm{MPa}$ compared to $7.2 \mathrm{MPa}$, and a Young's modulus of $364 \mathrm{MPa}$ compared to $73 \mathrm{MPa}$. A cell viability assay also confirmed the biocompatibility of the nanofiber web, indicating that the prepared nanocomposites had potential for use as wound dressing materials.
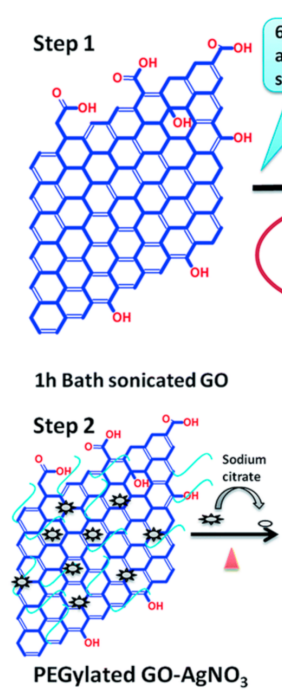

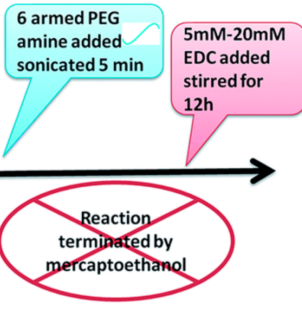

PEGylated GO in supernatant

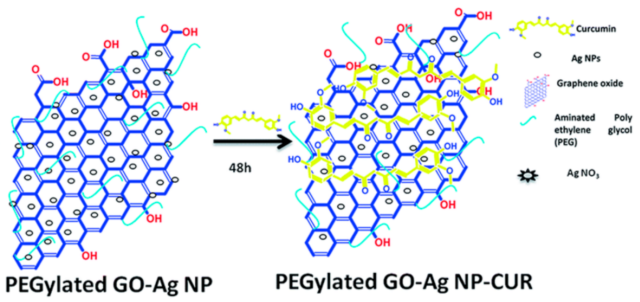

Figure 6. Schematic of synthesis of PEGylated GO and PEGylated-GO-based nanocomposites [2]. 
Some other preparations are also listed in Table 2.

Table 2. Chitosan/GO nanofiber webs and their biomedical applications.

\begin{tabular}{|c|c|c|c|}
\hline Ingredients & $\begin{array}{c}\text { Potential } \\
\text { Applications }\end{array}$ & Characterization & Reference \\
\hline $\begin{array}{l}\text { Chitosan/polyvinyl } \\
\text { pyrrolidone/ } \\
\text { polyethylene } \\
\text { oxide/GO }\end{array}$ & Wound dressings & $\begin{array}{c}\text { Enhanced elastic modulus and } \\
\text { tensile strength } \\
\text { Controllable water permeability } \\
\text { Biocompatible } \\
\text { Accelerated in vivo wound } \\
\text { closure rate }\end{array}$ & [54] \\
\hline $\begin{array}{l}\text { Chitosan/levorotatory } \\
\text { poly-L-lactide/GO }\end{array}$ & Wound dressings & $\begin{array}{l}\text { Excellent antimicrobial activity } \\
\text { Promoted proliferation of pig } \\
\text { iliac endothelial cells } \\
\text { Improved in vivo wound healing }\end{array}$ & [55] \\
\hline $\begin{array}{l}\text { Polyvinyl alcohol/ } \\
\text { chitosan/GO }\end{array}$ & $\begin{array}{l}\text { Tissue engineering, } \\
\text { wound healing, and } \\
\text { drug delivery } \\
\text { systems }\end{array}$ & $\begin{array}{l}\text { Improved mechanical properties } \\
\text { Effective antibacterial activity }\end{array}$ & [56] \\
\hline $\begin{array}{l}\text { Chitosan/bacterial } \\
\text { cellulose/GO }\end{array}$ & $\begin{array}{l}\text { Skin tissue } \\
\text { engineering and } \\
\text { wound dressing }\end{array}$ & $\begin{array}{l}\text { Adding GO reduced nanofiber } \\
\text { size } \\
\text { Water vapor permeability and } \\
\text { hydrophilicity decreased by } \\
\text { adding GO }\end{array}$ & [57] \\
\hline $\begin{array}{c}\text { Polylactide-co- } \\
\text { glycolide/chitosan/ } \\
\text { GO/silver } \\
\text { nanoparticles }\end{array}$ & $\begin{array}{l}\text { Biomedical } \\
\text { applications }\end{array}$ & $\begin{array}{l}\text { Improved wettability of } \\
\text { nanofibers } \\
\text { Enhanced antimicrobial function }\end{array}$ & [58] \\
\hline $\begin{array}{l}\text { Chitosan/gelatin/ } \\
\text { GO-silver }\end{array}$ & $\begin{array}{l}\text { Tissue engineering, } \\
\text { nanomedicine }\end{array}$ & $\begin{array}{l}\text { Improved tensile strength and } \\
\text { Young's modulus } \\
\text { Enhanced antimicrobial activity } \\
\text { Improved thermal stability }\end{array}$ & [59] \\
\hline
\end{tabular}

\subsection{Other Types of Chitosan/Graphene Oxide Composites}

Shao et al. [43] fabricated biocompatible graphene oxide nanocomposite membranes cross-linked with chitosan, which can be used in various applications. A schematic diagram of the reaction is shown in Figure 7. The tensile strength of the membranes was significantly improved with the incorporation of GO. By adding $1 \mathrm{wt} \% \mathrm{GO}$, tensile strength improved from $43.2 \mathrm{MPa}$ to $104.2 \mathrm{MPa}$, an increase of $141 \%$, which can be explained by the formation of covalent bonds formed during the chitosan/GO cross-linking reaction. The authors claimed that by controlling other physicochemical properties of GO, such as the density of the functional groups and particle size, superior nanocomposite properties could be achieved.

Chitosan/GO and chitosan/reduced GO (rGO) hybrid nanocomposites were fabricated by Kosowska et al. [60]. Reduced graphene oxide was synthesized by "green" reducing agents such as L-ascorbic acid (LAA), grape extract, and green tea extract. Among these three reducing agents, the nanocomposites prepared with rGO-LAA had good wettability and a regular, homogeneous microstructure, indicating that such nanocomposite materials may be considered as potential tissue-engineering scaffolds. The composites prepared from grape and green tea extracts were less homogenous and formed visible agglomerates. 


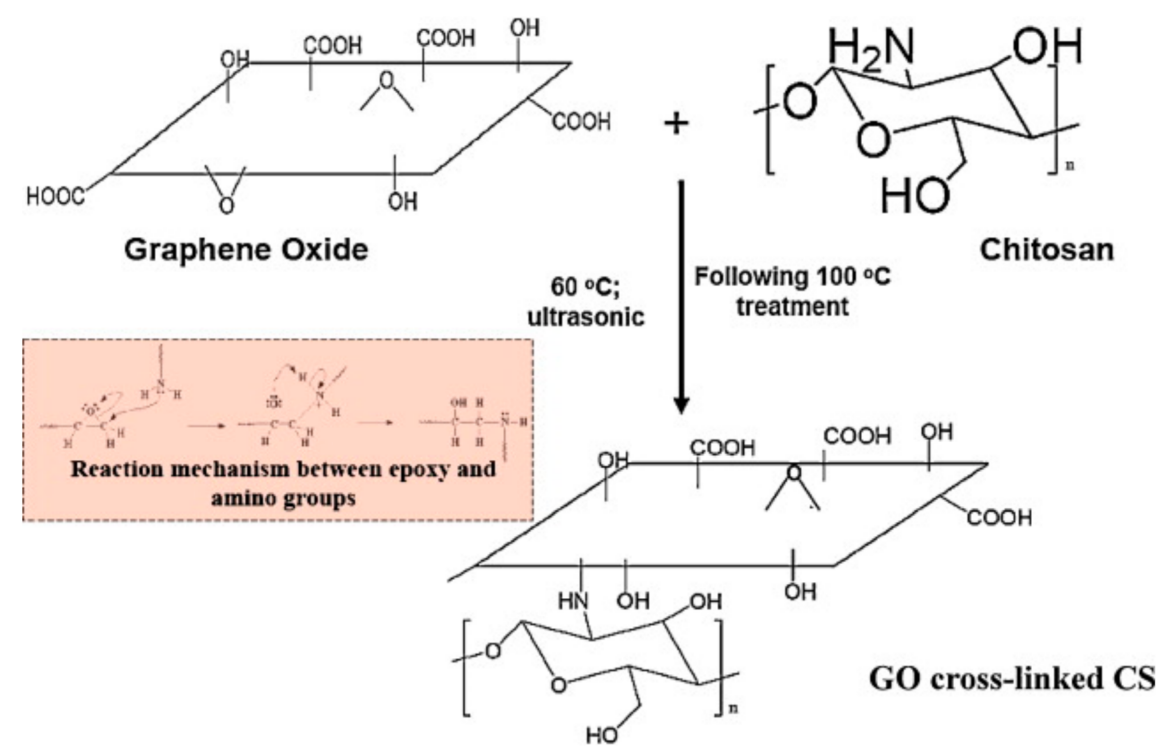

Figure 7. Cross-linking reaction between GO and CS to form nanocomposite membranes [43].

Chitosan/hyaluronic acid wound dressings were prepared with GO/copper using sodium trimeta-phosphate (STMP) as the crosslinking agent, followed by vacuum freezedrying [61]. The reason for using copper was that it is a cheaper antimicrobial agent with the ability to kill pathogens on its metallic surface. The prototype dressings had excellent antimicrobial activity against two strains of Staphylococcus aureus, usually found in wound infections, and good cytocompatibility when cultured with NIH/3T3-L1 mouse fibroblasts. The wound dressings loaded with copper provided a significantly faster rate of wound healing together with controlled inflammatory infiltration and improved angiogenesis in the regenerated surrounding granulation tissue. No adverse pathologies were observed when the tissues of other organs, such as the heart, lung, liver, or kidney, were examined.

A series of chitosan and graphene oxide (CS/GO) aerogels was developed as hemostatic agents by incorporating proanthocyanidins such as flavan-3-ols obtained from grape seed and skin extracts [62]. The aerogels were produced from solutions at two different pHs: acidic and alkaline. When exposed to whole blood, the acidic aerogels reached total absorption within the first $30 \mathrm{~s}$, and the alkaline aerogels within $60 \mathrm{~s}$. However, the structure of acidic aerogels was found to be unstable due to capillarity forces, which caused them to dissolve in the media. Therefore, the alkaline aerogels were considered more suitable as hemostatic agents due to their rigidity, porosity, superficial charge, PBS, and blood absorption capacities, as well as their stability in physiological media. These CS/GO aerogels promoted the accumulation of red blood cells through electrostatic interactions. The loaded aerogels showed slight cytotoxicity; however, the use of skin instead of grape seed extract increased cell viability, making them acceptable for hemostatic applications. However, the authors mentioned that additional studies are needed to realize the mechanisms that promote coagulation. Finally, they concluded that the prepared CS/GO aerogels could be considered for use as hemostatic agents in wound management.

\section{Chitosan/Graphene Oxide as a Drug Delivery Device}

Justin et al. [63] prepared chitosan/graphene oxide (CS/GO) nanocomposites, such as microneedle arrays, that were designed for transdermal drug delivery. The hybrid nanocomposite was found to provide faster and more effective drug release compared to pure chitosan, and the drug delivery profile was dependent on the ratio of the loaded drug. The drug release of these particular nanocomposites was also $\mathrm{pH}$ sensitive, with $48 \%$ less release under acidic conditions compared to a neutral environment. In another study, chitosan/sulfonated graphene oxide nanohybrid scaffolds were designed for drug delivery and as a tissue-engineering scaffold [64]. Greater hydrophilicity and improved 
mechanical properties were observed compared to chitosan alone. These nanohybrid prototype scaffolds had a uniform porous structure that facilitated the sustained release of an antimicrobial drug, tetracycline hydrochloride. In addition, they were highly biocompatible.

A genipin-crosslinked chitosan/graphene oxide (CS/GO) composite was prepared using a solution-casting method [65]. The presence of the GO decreased the expansion ratio of the composite film when exposed to physiological conditions and increased the resistance to in vitro degradation by lysozymes. A cell culture study using mouse MC3T3-E1 pre-osteoblasts showed positive adhesion and cell proliferation, and the prototype films were considered attractive candidates for tissue engineering and drug delivery applications. In another study, chitosan-functionalized graphene oxide hybrid nanosheets were synthesized and they demonstrated that the experimental nanosheets significantly improved the solubility of GO in aqueous acidic media [66]. They also provided controlled release of drugs, such as ibuprofen and 5-fluorouracil, and exhibited long-term biocompatibility, suggesting that these CS/GO-functionalized devices were suitable for biomedical applications such as drug delivery. Table 3 presents some other examples of the application of CS/GO films to serve as drug delivery devices.

Table 3. Application of chitosan/GO films to serve as drug delivery systems.

\begin{tabular}{|c|c|c|c|}
\hline Ingredients & Potential Applications & Characterization & Reference \\
\hline Chitosan/reduced GO & $\begin{array}{l}\text { Transdermal drug } \\
\text { delivery }\end{array}$ & $\begin{array}{l}\text { Enhanced electrical conductivity } \\
\text { pH dependent release behavior } \\
\text { rGO reduced biodegradation rate } \\
\text { Improved mechanical properties }\end{array}$ & [67] \\
\hline Chitosan/modified GO & Drug carrier & $\begin{array}{l}\text { Stability in aqueous acidic and } \\
\text { physiological solutions } \\
\text { Biocompatible } \\
\text { Excellent dispersibility }\end{array}$ & [68] \\
\hline $\begin{array}{l}\text { Aldehyde-conjugated } \\
\text { chitosan/GO }\end{array}$ & $\begin{array}{l}\text { Controlled chemical } \\
\text { release }\end{array}$ & $\begin{array}{l}\text { Improved mechanical properties } \\
\text { Time-dependent aromatic release }\end{array}$ & [69] \\
\hline $\begin{array}{l}\text { Chitosan/hydroxyethyl } \\
\text { cellulose/GO }\end{array}$ & $\begin{array}{l}\text { Drug delivery } \\
\text { application }\end{array}$ & $\begin{array}{l}\text { Stability over all pH ranges } \\
\text { Biocompatibility }\end{array}$ & {$[70]$} \\
\hline Chitosan/GO & $\begin{array}{l}\text { Delivery of } \\
\text { Proanthocyanidins * } \\
\text { (Ext.) }\end{array}$ & $\begin{array}{l}\text { Nontoxic to kidney cells } \\
\text { Thermostable } \\
\text { Biocompatibility of Ext. increased }\end{array}$ & [71] \\
\hline Chitosan/GO/Dextran & $\begin{array}{l}\text { Anti-cancer drug } \\
\text { delivery }\end{array}$ & $\begin{array}{l}\text { Increase release in acidic medium } \\
\text { (pH sensitivity behavior observed) } \\
\text { Strong cytotoxicity to cancer cells } \\
\text { Non-specific protein adsorption } \\
\text { decreased }\end{array}$ & [72] \\
\hline $\begin{array}{l}\text { Galactosylated } \\
\text { chitosan/GO }\end{array}$ & $\begin{array}{l}\text { Drug delivery system } \\
\text { for therapeutic } \\
\text { treatment of cancer }\end{array}$ & $\begin{array}{l}\text { Stable in physiological conditions } \\
\text { Higher fluorescence intensity in } \\
\text { tumor cells } \\
\text { Greater tumor cytotoxicity and better } \\
\text { tumor growth inhibition compared } \\
\text { to GO/GO derivatives }\end{array}$ & [73] \\
\hline $\begin{array}{l}\text { Chitosan/Silver } \\
\text { Nanoparticle/GO }\end{array}$ & Multi-Drug delivery & $\begin{array}{c}\mathrm{pH} \text { controlled single and/or dual } \\
\text { drug release } \\
\text { Strong antibacterial ability }\end{array}$ & [74] \\
\hline
\end{tabular}

\section{Clinical and Pre-Clinical Studies}

To the best of our knowledge, there are not yet any published reports describing clinical studies using chitosan/graphene oxide (CS/GO) hydrogels as wound dressings. There are some pre-clinical in vitro and in vivo studies in this field. For example, in one study, superior acute-wound healing was observed when CS/GO nanofibers were implanted in adult male rats [75]. The CS/GO nanofiber webs were prepared without any surfactants and organic solvents to make sure that the fibrous structure had excellent biocompatibility. In vitro evaluations with human skin fibroblasts indicated that the addition of GO 
improved cell viability with enhanced bactericidal capacity. In vivo wound healing studies on rat's skin demonstrated faster healing and full recovery of a $1.5 \times 1.5 \mathrm{~cm}^{2}$ open wound within 14 days. It is therefore recommended that these experimental CS/GO nanofiber webs have potential use in biomedical applications.

Other experimental wound dressings have been fabricated by incorporating polyhexamethylene guanidine and modified graphene oxide (mGO) into a polyvinyl alcohol/chitosan film [3]. In this in vivo study, cytotoxicity and wound healing were evaluated by applying $\mathrm{HaCaT}$ immortalized human keratinocyte cells to murine-infected full-thickness skin wounds. The results of the cytotoxicity test demonstrated good biocompatibility, and the films generated rapid wound healing through faster re-epithelialization. However, by increasing the concentration of $\mathrm{mGO}$ up to $1 \mathrm{wt} \%$, the proliferation of the $\mathrm{HaCaT}$ cells was prevented, and lower cytotoxicity was observed. In another in vivo study, rapid healing of dermal wounds was observed using a prototype wound dressing made of chitosan/L-polylactic acid/GO nanofibers [55].

Reports in the literature have shown that collagen/chitosan/graphene oxide films with the addition of basic fibroblast growth factor (bFGF) have been studied for wound healing applications [76]. bFGF was observed to provide continuous release for at least 28 days. No cytotoxic effects were found by adding $\mathrm{GO}$ to the films and, in fact, the addition of GO actually improved cytocompatibility. This in vivo murine wound study confirmed that the GO prototype films were capable of accelerating the wound healing process in comparison with the control group.

Alkylated chitosan/GO sponges have also been studied for their hemostatic effects, which can be used in wound healing applications [77]. The results of a rabbit femoral injury study showed higher hemostatic efficacy and promoted the adhesion of erythrocytes and platelets compared to the control samples. Additionally, by increasing the concentration of GO, blood clotting efficiency, platelet activation levels, and the release of intracellular $\mathrm{Ca}^{2+}$ all increased.

\section{Conclusions}

Wound healing involves the replacement of damaged or injured tissue of living organisms with newly regenerated tissue. Due to the complexity of the wound healing process, much effort has been focused on new approaches to wound management, such as fabricating a new generation of wound dressings. This review summarized chitosan/graphene oxide composite films and their potential applications as wound dressings and drug delivery devices. Chitosan is an attractive candidate due to its biodegradability, non-toxicity, and biocompatibility. Graphene oxide (GO) can be a substitute for carbon nanotubes or similar materials because of its lower price, low-toxicity, and ability to enhance mechanical properties. In addition, it promotes nerve regeneration in the case of deep wounds due to its excellent electrical conductivity. Composite or hybrid films composed of chitosan and graphene oxide can benefit from the advantages of both components, which makes them promising candidates for drug delivery and wound dressing applications.

Author Contributions: S.M.: Writing and Revising, H.H.: Writing and Revising, A.E.T.: Revising, M.W.K.: Revising. All authors have read and agreed to the published version of the manuscript.

Funding: This research received no external funding.

Institutional Review Board Statement: Not applicable.

Informed Consent Statement: Not applicable.

Data Availability Statement: Not applicable.

Conflicts of Interest: The authors declare no conflict of interest. 


\section{References}

1. Hamedi, H.; Moradi, S.; Hudson, S.M.; Tonelli, A.E. Chitosan based hydrogels and their applications for drug delivery in wound dressings: A review. Carbohydr. Polym. 2018, 199, 245-260. [CrossRef] [PubMed]

2. Dubeya, P.; Gopinath, P. PEGylated graphene oxide-based nanocomposite-grafted chitosan/polyvinyl alcohol nanofiber as an advanced antibacterial wound dressing. RSC Adv. 2016, 6, 69103-69116. [CrossRef]

3. Chen, S.; Wang, H.; Jian, Z.; Fei, G.; Qian, W.; Luo, G.; Wang, Z.; Xia, H. Novel Poly(vinyl alcohol)/Chitosan/Modified Graphene Oxide Biocomposite for Wound Dressing Application. Macromol. Biosci. 2020, 20, 1900385. [CrossRef] [PubMed]

4. He, Y.; Zhang, N.; Gong, Q.; Qiu, H.; Wang, W.; Liu, Y.; Gao, J. Alginate/graphene oxide fibers with enhanced mechanical strength prepared by wet spinning. Carbohydr. Polym. 2012, 88, 1100-1108. [CrossRef]

5. Chen, Y.; Qi, Y.; Yan, X.; Ma, H.; Chen, J.; Liu, B.; Xue, Q. Green fabrication of porous chitosan/graphene oxide composite xerogels for drug delivery. J. Appl. Polym. Sci. 2014, 131, 1-11. [CrossRef]

6. Moradi, S.; Barati, A.; Salehi, E.; Tonelli, A.; Hamedi, H. Preparation and Characterization of Chitosan Based Hydrogels Containing Cyclodextrin-Inclusion Compounds or Nanoemulsions of Thyme oil. Polym. Int. 2019, 68, 1891-1902. [CrossRef]

7. Hamedi, H.; Moradi, S.; Tonelli, A.; Hudson, S. Preparation and Characterization of Chitosan-Alginate Polyelectrolyte Complexes Loaded with Antibacterial Thyme Oil Nanoemulsions. Appl. Sci. 2019, 9, 3933. [CrossRef]

8. Moradi, S.; Barati, A.; Tonelli, A.E.; Hamedi, H. Chitosan-based hydrogels loading with thyme oil cyclodextrin inclusion compounds: From preparation to characterization. Eur. Polym. J. 2020, 122, 109303. [CrossRef]

9. Moradi, S.; Barati, A.; Tonelli, A.E.; Hamedi, H. Effect of clinoptilolite on structure and drug release behavior of chitosan/thyme oil $\gamma$-Cyclodextrin inclusion compound hydrogels. J. Appl. Polym. Sci. 2021, 138, 49822. [CrossRef]

10. Chung, C.; Kim, Y.; Shin, D.; Ryoo, S.; Hong, B.H.; Min, D. Biomedical Applications of Graphene and Graphene Oxide. Acc. Chem. Res. 2013, 46, 2211-2224. [CrossRef]

11. Lin, M.; Wang, Z.L.; Yang, P.W.; Li, P. Micro- structure and rheological properties of graphene oxide rubber asphalt. Nanotechnol. Rev. 2019, 8, 227-235. [CrossRef]

12. Chang, Y.; Yanga, S.; Liua, J.; Dong, E.; Wang, Y.; Cao, A.; Liua, Y.; Wang, H. In vitro toxicity evaluation of graphene oxide on A549 cells. Toxicol. Lett. 2011, 200, 201-210. [CrossRef]

13. LiQiang, C.; PingPing, H.; Li, Z.; SiZhou, H.; LingFei, L.; ChengZhi, H. Toxicity of graphene oxide and multi-walled carbon nanotubes against human cells and zebrafish. Sci. China Chem. 2012, 55, 2209-2216.

14. Majidi, H.J.; Babaei, A.; Bafrani, Z.A.; Shahrampour, D.; Zabihi, E.; Jafaric, S.M. Investigating the best strategy to diminish the toxicity and enhance the antibacterial activity of graphene oxide by chitosan addition. Carbohydr. Polym. 2019, 225, 115220. [CrossRef]

15. Liao, K.; Lin, Y.; Macosko, C.W.; Haynes, C.L. Cytotoxicity of Graphene Oxide and Graphene in Human Erythrocytes and Skin Fibroblasts. ACS Appl. Mater. Interfaces 2011, 3, 2607-2615. [CrossRef] [PubMed]

16. Seabra, A.B.; Paula, A.J.; de Lima, R.; Alves, O.L.; Durán, N. Nanotoxicity of Graphene and Graphene Oxide. Chem. Res. Toxicol. 2014, 27, 159-168. [CrossRef] [PubMed]

17. Wang, K.; Ruan, J.; Song, H.; Zhang, J.; Wo, Y.; Guo, S.; Cui, D. Biocompatibility of graphene oxide. Nanoscale Res. Lett. 2011, 6, 8 . [CrossRef] [PubMed]

18. Zhang, X.; Yin, J.; Peng, C.; Hu, W.; Zhu, Z.; Li, W.; Fan, C.; Huang, Q. Distribution and biocompatibility studies of graphene oxide in mice after intravenous administration. Carbon 2011, 49, 986-995. [CrossRef]

19. Kiew, S.F.; Kiew, L.V.; Lee, H.B.; Imae, T.; Chung, L.Y. Assessing biocompatibility of graphene oxide-based nanocarriers: A review. Release 2016, 226, 217-228. [CrossRef] [PubMed]

20. Dinescu, S.; Ionita, M.; Pandele, A.M.; Galateanu, B.; Iovu, H.; Ardelean, A.; Costache, M.; Hermenean, A. In vitro cytocompatibility evaluation of chitosan/graphene oxide 3D scaffold composites designed for bone tissue engineering. Bio-Med. Mater. Eng. 2014, 24, 2249-2256. [CrossRef]

21. Mukherjee, S.P.; Kostarelos, K.; Fadeel, B. Cytokine Profiling of Primary Human Macrophages Exposed to Endotoxin-Free Graphene Oxide: Size-Independent NLRP3 Inflammasome Activation. Adv. Healthc. Mater. 2018, 7, 1700815. [CrossRef]

22. Lee, H.; Kim, J.; Lee, J.; Park, H.; Park, Y.; Jung, S.; Lim, J.; Choi, H.C.; Kim, W.J. In vivo self-degradable graphene nanomedicine operated by DNAzyme and photo-switch for controlled anticancer therapy. Biomaterials 2020, 263, 120402. [CrossRef] [PubMed]

23. Li, Y.; Feng, L.; Shi, X.; Wang, X.; Yang, Y.; Yang, K.; Liu, T.; Yang, G.; Liu, Z. Surface Coating-Dependent Cytotoxicity and Degradation of Graphene Derivatives: Towards the Design of Non-Toxic, Degradable Nano—Graphene. Nano-Micro Small 2014, 10, 1544-1554. [CrossRef] [PubMed]

24. Tavakoli, M.; Karbasi, S.; Bakhtiari, S.S.E. Evaluation of physical, mechanical, and biodegradation of chitosan/graphene oxide composite as bone substitutes. Polym. Plast. Technol. Mater. 2020, 59, 430-440. [CrossRef]

25. Pandele, A.M.; Ionita, M.; Lungu, A.; Vasile, E.; Zaharia, C.; Iovu, H. Porous chitosan/graphene oxide biocomposites for tissue engineering. Polym. Compos. 2017, 38, 363-370. [CrossRef]

26. Gurunathan, S.; Han, J.W.; Dayem, A.A.; Eppakayala, V.; Kim, J. Oxidative stress-mediated antibacterial activity of graphene oxide and reduced graphene oxide in Pseudomonas aeruginosa. Int. J. Nanomed. 2012, 7, 5901-5914. [CrossRef] [PubMed]

27. Liu, S.; Hu, M.; Zeng, T.H.; Wu, R.; Jiang, R.; Wei, J.; Wang, L.; Kong, J.; Chen, Y. Lateral Dimension-Dependent Antibacterial Activity of Graphene Oxide Sheets. Langmuir 2012, 28, 12364-12372. [CrossRef] [PubMed] 
28. Liu, S.; Zeng, T.H.; Hofmann, M.; Burcombe, E.; Wei, J.; Jiang, R.; Kong, J.; Chen, Y. Antibacterial Activity of Graphite, Graphite Oxide, Graphene Oxide, and Reduced Graphene Oxide: Membrane and Oxidative Stress. ACS Nano 2011, 5, 6971-6980. [CrossRef]

29. Mukherjee, S.; Sriram, P.; Barui, A.K.; Nethi, S.K.; Veeriah, V.; Chatterjee, S.; Suresh, K.I.; Patra, C.R. Graphene Oxides Show Angiogenic Properties. Adv. Healthc. Mater. 2015, 4, 1722-1732. [CrossRef]

30. Rehman, S.R.; Augustine, R.; Zahid, A.A.; Ahmed, R.; Tariq, M.; Hasan, A. Reduced Graphene Oxide Incorporated GelMA Hydrogel Promotes Angiogenesis for Wound Healing Applications. Int. J. Nanomed. 2019, 14, 9603-9617. [CrossRef]

31. Chhabra, P.; Chauhan, G.; Kumar, A. Augmented healing of full thickness chronic excision wound by rosmarinic acid loaded chitosan encapsulated graphene nanopockets. Drug Dev. Ind. Pharm. 2020, 46, 878-888. [CrossRef]

32. Ozkan, B.C.; Soganci, T.; Turhan, H.; Akb, M. Investigation of rGO and chitosan effects on optical and electrical properties of the conductive polymers for advanced applications. Electrochim. Acta 2019, 295, 1044-1051. [CrossRef]

33. Wang, X.; Bai, H.; Yao, Z.; Liua, A.; Shi, G. Electrically conductive and mechanically strong biomimetic chitosan/reduced graphene oxide composite films. J. Mater. Chem. 2010, 20, 9032-9036. [CrossRef]

34. Betriu, X.D.; García, S.Á.; Botas, C.; Álvarez, P.; Marcos, J.S.; Prieto, C.; Menéndez, R.; de Andrés, A. Raman spectroscopy for the study of reduction mechanisms and optimization of conductivity in graphene oxide thin films. J. Mater. Chem. C 2013, 1, 6905-6912. [CrossRef]

35. Jiang, L.; Chen, D.; Wang, Z.; Zhang, Z.; Xia, Y.; Xue, H.; Liu, Y. Preparation of an Electrically Conductive Graphene Oxide/Chitosan Scaffold for Cardiac Tissue Engineering. Appl. Biochem. Biotechnol. 2019, 188, 952-964. [CrossRef] [PubMed]

36. Jing, X.; Mi, H.Y.; Napiwocki, B.N.; Peng, X.F.; Turng, L.S. Mussel-inspired electroactive chitosan/graphene oxide composite hydrogel with rapid self-healing and recovery behavior for tissue engineering. Carbon 2017, 125, 557-570. [CrossRef]

37. Zhou, M.; Zhai, Y.; Dong, S. Electrochemical Sensing and Biosensing Platform Based on Chemically Reduced Graphene Oxide. Anal. Chem. 2009, 81, 5603-5613. [CrossRef]

38. Zhang, D.; Tong, J.; Xia, B. Humidity-sensing properties of chemically reduced graphene oxide/polymer nanocomposite film sensor based on layer-by-layer nano self-assembly. Sens. Actuators B Chem. 2014, 197, 66-72. [CrossRef]

39. Zhao, S.; Zhang, H.; Luo, J.; Wang, Q.; Xu, B.; Hong, S.; Yu, Z. Highly Electrically Conductive Three-Dimensional Ti ${ }_{3} \mathrm{C}_{2} \mathrm{~T}_{\mathrm{x}}$ MXene/Reduced Graphene Oxide Hybrid Aerogels with Excellent Electromagnetic Interference Shielding Performances. ACS Nano 2018, 12, 11193-11202. [CrossRef]

40. Li, Z.J.; Yang, B.C.; Zhang, S.R.; Zhao, C.M. Graphene oxide with improved electrical conductivity for supercapacitor electrodes. Appl. Sci. Surf. 2012, 258, 3726-3731. [CrossRef]

41. Shin, S.R.; Zihlmann, C.; Akbari, M.; Assawes, P.; Cheung, L.; Zhang, K.; Manoharan, V.; Zhang, Y.S.; Wan, M.Y.K.; Nikkhah, M.; et al. Reduced Graphene Oxide-GelMA Hybrid Hydrogels as Scaffolds for Cardiac Tissue Engineering. Nano-Micro Small 2016, 12, 3677-3689. [CrossRef]

42. Norahan, M.H.; Amroon, M.; Ghahremanzadeh, R.; Mahmoodi, M.; Baheiraei, N. Electroactive graphene oxide-incorporated collagen assisting vascularization for cardiac tissue engineering. J. Biomed. Mater. Res. Part A 2019, 107, 204-219. [CrossRef]

43. Shao, L.; Chang, X.; Zhang, Y.; Huang, Y.; Yao, Y.; Guo, Z. Graphene oxide cross-linked chitosan nanocomposite membrane. Appl. Surf. Sci. 2013, 280, 989-992. [CrossRef]

44. Fan, L.; Yi, J.; Tong, J.; Zhou, X.; Ge, H.; Zou, S.; Wen, H.; Nie, M. Preparation and characterization of oxidized konjac glucomannan/carboxymethyl chitosan/graphene oxide hydrogel. Int. J. Biol. Macromol. 2016, 91, 358-367. [CrossRef] [PubMed]

45. Zhang, Y.; Zhang, M.; Jiang, H.; Shi, J.; Li, F.; Xia, Y.; Zhang, G.; Li, H. Bio-inspired layered chitosan/graphene oxide nanocomposite hydrogels with high strength and $\mathrm{pH}$-driven shape memory effect. Carbohydr. Polym. 2017, 177, 116-125. [CrossRef]

46. Nowroozi, N.; Faraji, S.; Nouralishahi, A.; Shahrousvand, M. Biological and structural properties of graphene oxide/curcumin nanocomposite incorporated chitosan as a scaffold for wound healing application. Life Sci. 2021, 1, 118640. [CrossRef]

47. Konwar, A.; Kalita, S.; Kotoky, J.; Chowdhury, D. Chitosan-Iron Oxide Coated Graphene Oxide Nanocomposite Hydrogel: A Robust and Soft Antimicrobial Biofilm. ACS Appl. Mater. Interfaces 2016, 8, 20625-20634. [CrossRef] [PubMed]

48. Chen, Y.; Wang, H.; Yu, J.; Wang, Y.; Zhu, J.; Hu, Z. Mechanically strong and pH-responsive carboxymethyl chitosan/graphene oxide/polyacrylamide nanocomposite hydrogels with fast recoverability. J. Biomater. Sci. Polym. Ed. 2017, 28, 1899-1917. [CrossRef] [PubMed]

49. Zhang, B.; He, J.; Shi, M.; Liang, Y.; Guoabc, B. Injectable self-healing supramolecular hydrogels with conductivity and photothermal antibacterial activity to enhance complete skin regeneration. Chem. Eng. J. 2020, 400, 125994. [CrossRef]

50. Yang, M.; Tseng, Y.; Liu, K.; Cheng, Y.; Chen, W.; Chen, W.; Hsiao, C.; Yung, M.; Hsu, C.; Liu, T. Preparation of Amphiphilic Chitosan-Graphene Oxide-Cellulose Nanocrystalline Composite Hydrogels and Their Biocompatibility and Antibacterial Properties. Appl. Sci. 2019, 9, 3051. [CrossRef]

51. Khalili, R.; Zarrintaj, P.; Jafari, S.H.; Vahabi, H.; Saeb, M.R. Electroactive poly (p-phenylene sulfide)/r-graphene oxide/chitosan as a novel potential candidate for tissue engineering. Macromolecules 2020, 154, 18-24. [CrossRef]

52. Yang, S.; Zhang, X.; Zhang, D. Electrospun Chitosan/Poly (Vinyl Alcohol)/Graphene Oxide Nanofibrous Membrane with Ciprofloxacin Antibiotic Drug for Potential Wound Dressing Application. Int. J. Mol. Sci. 2019, 20, 4395. [CrossRef]

53. Yang, S.; Lei, P.; Shan, Y.; Zhang, D. Preparation and characterization of antibacterial electrospun chitosan/poly (vinyl alcohol)/graphene oxide composite nanofibrous membrane. Appl. Surf. Sci. 2018, 435, 832-840. [CrossRef]

54. Mahmoudi, N.; Simchi, A. On the biological performance of graphene oxide-modified chitosan/polyvinyl pyrrolidone nanocomposite membranes: In vitro and in vivo effects of graphene oxide. Mater. Sci. Eng. C 2017, 70, 121-131. [CrossRef] 
55. Yang, C.; Yan, Z.; Lian, Y.; Wang, J.; Zhang, K. Graphene oxide coated shell-core structured chitosan/PLLA nanofibrous scaffolds for wound dressing. J. Biomater. Sci. Polym. Ed. 2020, 31, 622-641. [CrossRef]

56. Liu, Y.; Park, M.; Shin, H.K.; Pant, B.; Choi, J.; Park, Y.W.; Lee, J.Y.; Park, S.; Kim, H. Facile preparation and characterization of poly(vinyl alcohol)/chitosan/graphene oxide biocomposite nanofibers. J. Ind. Eng. Chem. 2014, 20, 4415-4420. [CrossRef]

57. Azarniya, A.; Eslahi, N.; Mahmoudi, N.; Simchi, A. Effect of graphene oxide nanosheets on the physico-mechanical properties of chitosan/bacterial cellulose nanofibrous composites. Compos. Part A Appl. Sci. Manuf. 2016, 85, 113-122. [CrossRef]

58. de Faria, A.F.; Perreault, F.; Shaulsky, E.; Chavez, L.H.A.; Elimelech, M. Antimicrobial Electrospun Biopolymer Nanofiber Mats Functionalized with Graphene Oxide-Silver Nanocomposites. ACS Appl. Mater. Interfaces 2015, 7, 12751-12759. [CrossRef] [PubMed]

59. Cai, N.; Zeng, H.; Fu, J.; Chan, V.; Chen, M.; Li, H.; Yu, F. Synergistic effect of graphene oxide-silver nanofillers on engineering performances of polyelectrolyte complex nanofiber membranes. J. Appl. Polym. Sci. 2018, 135, 46238. [CrossRef]

60. Kosowska, K.; Domalik-Pyzik, P.; Nocun, M.; Chłopek, J. Chitosan and graphene oxide/reduced graphene oxide hybrid nanocomposites-Evaluation of physicochemical properties. Mater. Chem. Phys. 2018, 216, 28-36. [CrossRef]

61. Yang, Y.; Dong, Z.; Li, M.; Liu, L.; Luo, H.; Wang, P.; Zhang, D.; Yang, X.; Zhou, K.; Lei, S. Graphene Oxide/Copper Nanoderivatives-Modified Chitosan/Hyaluronic Acid Dressings for Facilitating Wound Healing in Infected Full-Thickness Skin Defects. Int. J. Nanomed. 2020, 15, 8231-8247. [CrossRef] [PubMed]

62. Figueroa, T.; Carmona, S.; Guajardo, S.; Borges, J.; Aguayo, C.; Fernández, K. Synthesis and characterization of graphene oxide chitosan aerogels reinforced with flavan-3-ols as hemostatic agents. Colloids Surf. B Biointerfaces 2021, 197, 111398. [CrossRef]

63. Justin, R.; Chen, B. Characterisation and drug release performance of biodegradable chitosan-graphene oxide nanocomposites. Carbohydr. Polym. 2014, 103, 70-80. [CrossRef]

64. Mahanta, A.K.; Patel, D.K.; Maiti, P. Nanohybrid Scaffold of Chitosan and Functionalized Graphene Oxide for Controlled Drug Delivery and Bone Regeneration. ACS Biomater. Sci. Eng. 2019, 5, 5139-5149. [CrossRef] [PubMed]

65. Li, J.; Ren, N.; Qiu, J.; Mou, X.; Liu, H. Graphene oxide-reinforced biodegradable genipin-cross-linked chitosan fluorescent biocomposite film and its cytocompatibility. Int. J. Nanomed. 2013, 8, 3415-3426. [CrossRef] [PubMed]

66. Rana, V.K.; Choi, M.; Kong, J.; Kim, G.Y.; Kim, M.J.; Kim, S.; Mishra, S.; Singh, R.P.; Ha, C. Synthesis and Drug-Delivery Behavior of Chitosan-Functionalized Graphene Oxide Hybrid Nanosheets. Macromol. Mater. Eng. 2011, 296, 131-140. [CrossRef]

67. Justin, R.; Chen, B. Strong and conductive chitosan-reduced graphene oxide nanocomposites for transdermal drug delivery. J. Mater. Chem. B 2014, 2, 3759-3770. [CrossRef] [PubMed]

68. Jia, J.; Gai, Y.; Wang, W.; Zhao, Y. Green synthesis of biocompatiable chitosan-graphene oxide hybrid nanosheet by ultrasonication method. Ultrason. Sonochem. 2016, 32, 300-306. [CrossRef]

69. Chabbi, J.; Aqil, A.; Katir, N.; Vertruyen, B.; Jerôme, C.; Lahcini, M.; el Kadib, A. Aldehyde-conjugated chitosan-graphene oxide glucodynamers: Ternary cooperative assembly and controlled chemical release. Carbohydr. Polym. 2020, 230, 115634. [CrossRef] [PubMed]

70. Mianehrow, H.; Afshari, R.; Mazinani, S.; Sharif, F.; Abdouss, M. Introducing a highly dispersed reduced graphene oxide nano-biohybrid employing chitosan/hydroxyethyl cellulose for controlled drug delivery. Int. J. Pharm. 2016, 509, 400-407. [CrossRef]

71. Figueroa, T.; Aguayo, C.; Fernández, K. Design and Characterization of Chitosan-Graphene Oxide Nanocomposites for the Delivery of Proanthocyanidins. Int. J. Nanomed. 2020, 15, 1229-1238. [CrossRef] [PubMed]

72. Xie, M.; Lei, H.; Zhang, Y.; Xu, Y.; Shen, S.; Ge, Y.; Li, H.; Xie, J. Non-covalent modification of graphene oxide nanocomposites with chitosan/dextran and its application in drug delivery. RSC Adv. 2016, 6, 9328-9337. [CrossRef]

73. Wang, C.; Zhang, Z.; Chen, B.; Gu, L.; Li, Y.; Yu, S. Design and evaluation of galactosylated chitosan/graphene oxide nanoparticles as a drug delivery system. J. Colloid Interface Sci. 2018, 516, 332-341. [CrossRef] [PubMed]

74. Su, Z.; Sun, D.; Zhang, L.; He, M.; Jiang, Y.; Millar, B.; Douglas, P.; Mariotti, D.; Maguire, P.; Sun, D. Chitosan/Silver Nanoparticle/Graphene Oxide Nanocomposites with Multi-Drug Release, Antimicrobial, and Photothermal Conversion Functions. Materials 2021, 14, 2351. [CrossRef] [PubMed]

75. Mahmoudi, N.; Eslahi, N.; Mehdipour, A.; Mohammadi, M.; Akbari, M.; Kuchaksaraei, A.S.; Simchi, A. Temporary skinskin grafts based on hybrid graphene oxide-natural biopolymer nanofibers as effective wound healing substitutes: Pre-clinical and pathological studies in Animal Models. J. Mater. Sci. Mater. Med. 2017, 28, 73. [CrossRef]

76. Liu, T.; Dan, W.; Dan, N.; Liu, X.; Liu, X.; Peng, X. A novel grapheme oxide-modified collagen-chitosan bio-film for controlled growth factor release in wound healing applications. Mater. Sci. Eng. C 2017, 77, 202-211. [CrossRef]

77. Zhang, Y.; Guan, J.; Wu, J.; Ding, S.; Yang, J.; Zhang, J.; Dong, A.; Deng, L. N-alkylated chitosan/graphene oxide porous sponge for rapid and effective hemostasis in emergency situations. Carbohydr. Polym. 2019, 219, 405-413. [CrossRef] [PubMed] 